\title{
Prospective study on health-related quality of life in patients before and after cochlear implantation
}

\author{
Michaela Plath ${ }^{1}$ (I) $\cdot$ Theresa Marienfeld $^{1} \cdot$ Matthias Sand $^{2} \cdot$ Philipp S. van de Weyer $^{1} \cdot$ Mark Praetorius $^{3}$. \\ Peter K. Plinkert ${ }^{1} \cdot$ Ingo Baumann $^{1} \cdot$ Karim Zaoui ${ }^{1}$
}

Received: 13 July 2020 / Accepted: 20 January 2021 / Published online: 9 February 2021

(C) The Author(s) 2021

\begin{abstract}
Purpose Assessing cochlear implant (CI)-associated patient outcomes is a focus of implant research. Most studies have analyzed outcomes retrospectively with low patient numbers and few measurement time points. In addition, standardized CI-specific health-related quality of life (HRQoL) instruments have not been used. To address this, we prospectively assessed HRQoL in patients before and after implantation.

Methods We assessed HRQoL using the Nijmegen Cochlear Implant Questionnaire (NCIQ), Abbreviated Profile of Hearing Aid Benefit (APHAB), Hearing Participation Scale (HPS), and the Visual Analogue Scale (VAS) in 100 deaf or severely hearing-impaired patients (57 unilaterally deaf and 43 bilaterally deaf) before and 3, 6, and 12 months after cochlear implantation. We compared the results of unilaterally and bilaterally hearing-impaired patients and patients with or without a hearing aid. Principal component (PCA) and exploratory factor analyses (EFA) were also conducted.

Results The NCIQ measured improvements in all 6 domains after CI and correlated well with other QoL instruments. The PCA revealed that the NCIQ can be better explained by physical, physical advanced, and socio-psychological components. The APHAB score ameliorated over time, except for the background noise domain. The overall HPS score improved over time, but the hearing handicap subscore significantly decreased. Sociodemographic influences on the questionnaire scores were relatively weak.

Conclusion Assessing HRQoL is essential for quantifying the patient outcome after CI. NCIQ scores in our patient cohort showed improved HRQoL in all domains and we recommend that the NCIQ be used as a first-line questionnaire for assessing QoL in hearing-impaired patients after CI.
\end{abstract}

Keywords HRQoL $\cdot$ Cochlear implant $\cdot$ NCIQ $\cdot$ APHAB $\cdot$ HPS $\cdot$ Prospective data

\section{Introduction}

Hearing loss is the third most common chronic condition in adults and has serious health-related implications [1-3]. Fewer relationships, decreased social activity, and increased

Michaela Plath

michaela.plath@med.uni-heidelberg.de

1 Department of Otorhinolaryngology, Head and Neck Surgery, University Hospital Heidelberg, Ruprecht-KarlsUniversity, Im Neuenheimer Feld 400, 69120 Heidelberg, Germany

2 GESIS-Leibniz-Institute for the Social Sciences, Mannheim, Germany

3 Department of Otorhinolaryngology, Head and Neck Surgery, University Hospital Hamburg, Hamburg, Germany depression are the psycho-social consequences of untreated hearing loss [4, 5]. Cochlear implants (CI) can restore hearing in people with severe or total hearing loss when hearing aids have little or no effect [6]. They may also improve speech recognition and quality of life (QoL) [1, 7-13]. However, the quality of studies on this topic is low, and the type and frequency of complications and side effects have not been investigated [6]. In recent years, research focus has shifted to the health-related quality of life (HRQoL) after cochlear implantation. Some studies have retrospectively analyzed improvements in hearing ability, speech perception, and speech production [14-17], but cochlear implantation also affects the social life and self-esteem of patients [18]. So far, there is no standardized questionnaire for assessing HRQoL after cochlear implantation [19, 20]. Authors have used either the Nijmegen Cochlear Implant 
Questionnaire (NCIQ) [21] or the Patient Quality of Life Form and Index Relative Questionnaire Form (IRQF) [22] to measure HRQoL after cochlear implantation [18].

The aim of the present study was to prospectively assess the HRQoL in unilaterally or bilaterally hearing-impaired patients with or without a hearing aid following cochlear implantation. To assess the effect of a CI on functional outcomes and well-being, we used the NCIQ, Abbreviated Profile of Hearing Aid Benefit (APHAB), and Hearing Participation Scale (HPS). Patient data were examined prospectively using an exploratory, longitudinal study design. Questionnaires were completed before implantation and 3, 6 , and 12 months after implantation.

\section{Materials and methods}

\section{Ethical considerations}

The ethics committee of the Medical Faculty at the University of Heidelberg granted permission to conduct the study (project no S-481/2009). The study was performed according to the Declaration of Helsinki on biomedical research involving human subjects. All patients were informed about the study aims and protocol, and participants were enrolled after giving informed written consent.

\section{Patient recruitment and patient data}

All patients fitted with a cochlear implant at our department between 2011 and 2013 were considered for inclusion in the study. Implant systems were manufactured by MED-EL, Cochlear, and Advanced Bionics, and all implants were fitted by one of the authors (Ma. P.). Inclusion criteria were unilaterally or bilaterally deafness or severely hearing impairment and $\geq 18$ years of age, and exclusion criteria were any medical condition requiring medication or surgical therapy and not giving consent to participate in the study. Surgical and clinico-pathological characteristics (age, gender, surgical report, implant systems, marital status, smoking habits, education, and professional activities) were recorded. Hearing performances were not included in our evaluation. All data were pseudonymized. For the investigations of the respective influencing factors on the questionnaire results, the patient cohort $(n=100)$ was divided into uni- $(n=57)$ and bilaterally $(n=43)$ deaf patients and into patients with $(n=54)$ or without hearing aids $(n=46)$.

\section{HRQoL assessment}

Patients' HRQoL was subjectively assessed using two established and validated questionnaires (NCIQ and APHAB) before implantation. In addition to the NCIQ and APHAB, the HPS and VAS questionnaires were used to assess QoL at 3, 6, and 12 months after implantation. The NCIQ is a standard questionnaire for assessing the QoL in patients fitted with CIs, and is reliable and sensitive to clinical changes $[1,8,13,21]$. It comprises 60 questions divided into three general domains with respective subdomains: physical (basic sound perception, advanced sound perception, and speech production); psychological (self-esteem); and social (limited activity and social interaction [21]. Scores range from 0 (extremely poor) to 100 (excellent) [23]. The APHAB questionnaire is an abbreviated version of the Profile of Hearing Aid Benefit, which was originally designed to measure the benefit a patient gains from using a hearing aid. The APHAB comprises 24 questions, each with seven possible answers. Each question is answered twice - with and without a hearing aid. The questions are internally divided into four subscales: ease of communication (EC), background noise (BN), reverberation (RB), and aversiveness of noise (AV) [24]. A lower value indicates a better result [25]. The HPS is a shortened form of the Glasgow Health Status Inventory and includes 11 items covering three dimensions: self-esteem (questions 1-4 and 11), social handicap (questions 5-8), and hearing handicap (questions 9-11) [19]. Scores range from 0.00 to 1.00. A high score (maximum 55) indicates low impairment and a low score indicates high impairment or social handicap [26]. Satisfaction with the CI was assessed by the Visual Analogue Scale (VAS). Patients marked the subjective value applicable to them as a horizontal line on a scale from 0 (very unsatisfied) to $100 \%$ (very satisfied). The VAS has good validity [27], and is widely used in pain research and therapy.

\section{Statistical analysis}

Statistical analysis was performed at the GESIS-LeibnizInstitute for the Social Sciences. Data were analyzed using the statistical software R (version 3.6.1). Principal component analysis (PCA) and exploratory factor analysis (EFA) were conducted using psych, nFactor and FactoMineR libraries. To determine the number of main components, graphical and non-graphical PCAs were used, including scree plots, eigenvalue analysis, parallel analysis, and optimal coordinates as suggested by Kaiser [28] and Cattell [29]. Both PCA and EFA are ways to simplify a particular set of data (in our case the genuine items that were measured for a particular index) by reducing the dimensionality of the initial data set. This is achieved by condensing the initial data into principal components that each contain variables of the data set that are highly correlated and therefore measure the same construct. These components then contain a linear combination of the related items/variables. The optimal number of components can be determined by the increment of the overall explained variation 
of the data by the newly formed orthogonal combination of the principal components [30]. We used this method to test whether our data fit the arrangement of subindices already established by the literature.

Sociodemographic characteristics were analyzed using generalized regression models. Metric variables are presented as means \pm standard deviation, and categorical variables are presented as absolute numbers and percentages. Potential differences between groups (e.g., unilateral vs. bilateral hearing loss; hearing aid vs. no hearing aid) were examined using the Wilcoxon test for nonparametric data and Student's test for parametric data. Differences in questionnaire scores between groups were determined using paired $t$ test and one-way ANOVA. A $p$ value less than 0.05 was considered statistically significant. Patient data were analyzed and compared. Each index and its subindices were graphically compared using R's ggplot 2 package.

To determine the relatedness between the various questionnaire inventories, we performed the Pearson's product-moment correlation test and the $\chi^{2}$ test for independence between each of the indices and time points.

\section{Results}

\section{Patient cohort}

A total of 100 deaf and severely hearing-impaired patients (54 females, 46 males) undergoing cochlear implantation were included in this prospective monocentric study. The average age at the time of implantation was $55.3 \pm 16.9$ years. Fifty-seven patients had unilateral deafness and 43 patients had bilateral deafness. Fifty-four patients used a hearing aid and 46 patients did not. The average duration of deafness was $213.2 \pm 203.6$ months (range 2-659). Eighty-five patients (85\%) completed the 3-month follow-up, $65 \%$ completed the 6-month follow-up, and at 12 months, the dropout rate was approximately $41 \%$, leading to $59 \%$ of remaining participants. Due to the small amount of initial data points, which is accompanied by a larger variance of estimates, an in-depth analysis of attritors was dismissed. However, Lugtig [31] argues that most reasons of attrition can be contributed to socio-demographic (e.g., age or gender), sociopsychological (e.g., a break in the habit of answering to the survey or absence of commitment), or (external) "shocks" such as health issues or moving. Hence, there is a possibility that aside of the negative impact of these dropouts on an estimator's variance, it may further impact the (un-) biasedness of an estimator due to systematic reasons.

Figure 1 and Table 1 illustrate the patient scores for the (sub)domains of each QoL instrument.

\section{VAS score}

The postoperative VAS scores showing patient satisfaction were stable over time and did not differ between the follow-ups. VAS scores were not different between patients who used a hearing aid and those who did not. Bilaterally deaf patients had significantly higher VAS scores than unilaterally deaf patients over time ( 81.9 vs. 71.2 at 3,6 and 12 months; $p=0.01$ ), indicating higher levels of satisfaction. The degree of deafness (unilateral vs. bilateral) significantly influenced the VAS score at 3 months ( $\widehat{\beta}=13.46, p=0.02)$, and age significantly influences the VAS score at 12 months $(\hat{\beta}=0.48, p=0.04)$.

\section{Nijmegen Cochlear Implant Questionnaire (NCIQ)}

As shown in Fig. 1a and Table 1, the overall NCIQ score significantly increased after cochlear implantation. The difference was highest in the basic sound perception subdomain and lowest in the advanced sound perception subdomain. Preoperative NCIQ scores were significantly different to the postoperative scores in the total cohort $(n=100)$. Uni- and bilaterally deaf patients only differed significantly preoperatively ( 54.3 vs. $42.8 ; p<0.001)$ but not postoperatively. Wearing a hearing aid did not significantly affect the NCIQ score at any time point. When focusing on the three NCIQ (sub)domains, we could demonstrate that patients without a hearing aid had significantly higher scores in the physical domain before implantation ( 51.1 vs. $62.5 ; p<0.01)$ and at 12 months follow-up (72.9 vs. $80.2 ; p=0.05$ ). Unilaterally deaf patients had significantly higher scores in the physical domain before implantation (63.9 vs. $46.4 ; p<0.01$ ) and 3 months after implantation (73.6 vs. $65.9 ; p=0.03$ ) than bilaterally deaf patients did. These findings suggest that unilaterally deaf patients who do not wear a hearing aid benefit less physically from the cochlear implantation than bilaterally deaf patients who wear a hearing aid do, because the scores for the physical domain remain mostly at baseline. Scores in the social and psychological domains were not significantly different between the groups $(p>0.05)$ at all points of measurement. Concerning the socio-demographic domain, whether hearing impairment was unilateral or bilateral only had a significant effect on the physical subscore before implantation $(\hat{\beta}=-12.78, p<0.01)$. Professional activity affected the physical subscore 3 months after implantation $(\hat{\beta}=-4.11, p=0.03)$. Scores in the social domain were significantly affected by graduation (preoperatively: $\widehat{\beta}=4.3, p=0.04)$, professional activity $(\hat{\beta}=-3.63$, $p=0.05)$, and age $(\hat{\beta}=-0.3, p=0.03)$ at 3 months after implantation. The duration of deafness significantly influenced the score in the psychological domain 6 months after implantation $(\hat{\beta}=-0.02, p=0.04)$. 
A

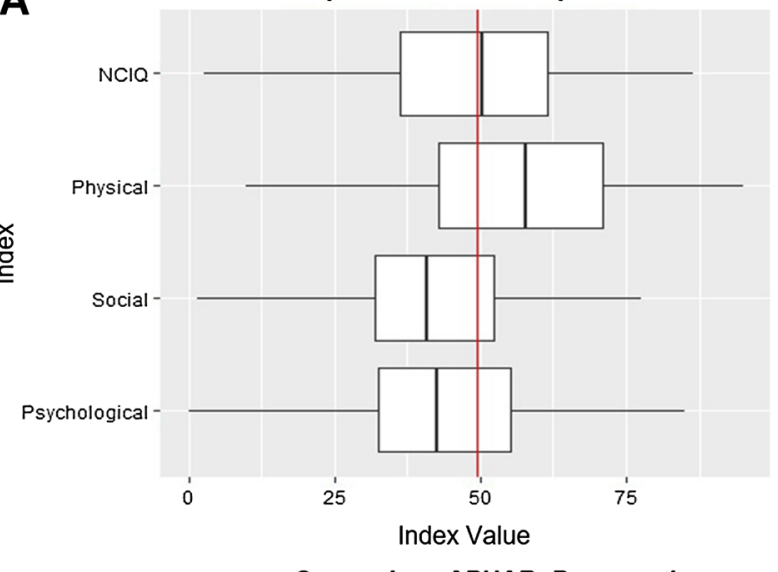

B

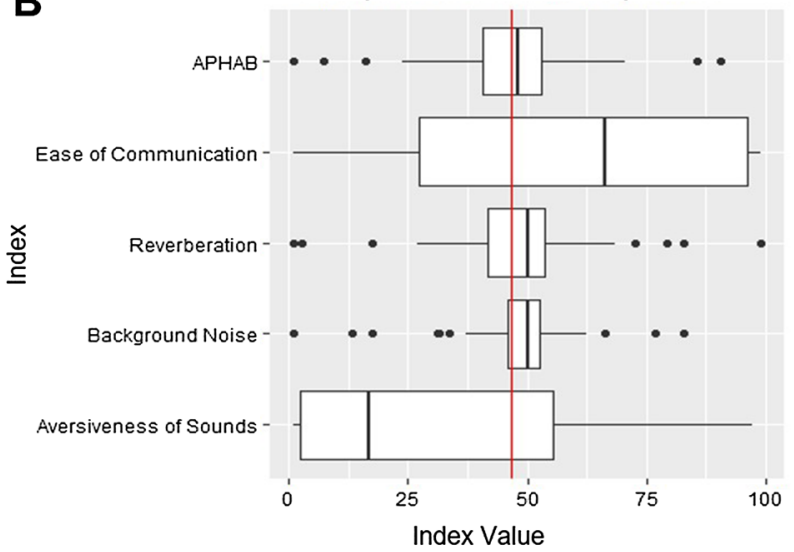

C
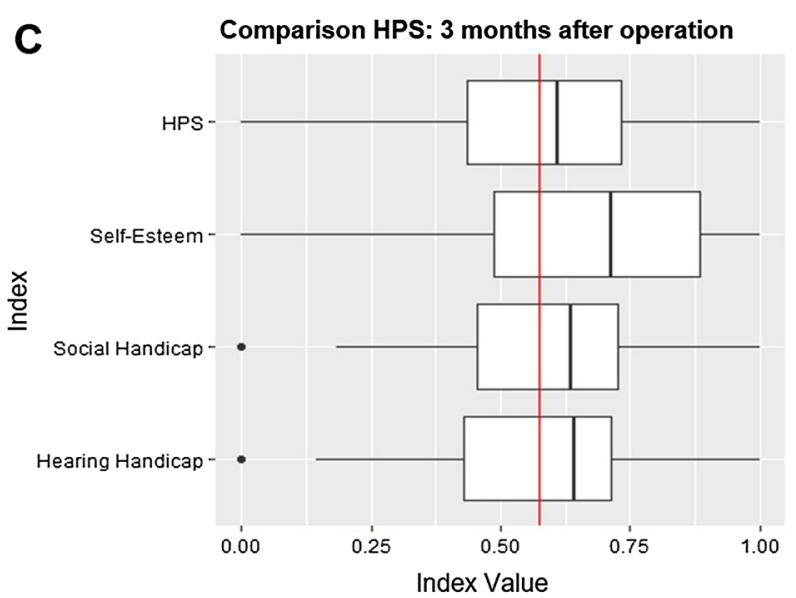

Fig. 1 Box plot illustration of the used questionnaires. a Box plot illustration of the NCIQ total score and its three domains (physical, social, and psychological) at different time points (preoperative and 12 months after operation) of the total patient cohort $(n=100)$. The red line represents the overall mean NCIQ score. The bold line shows each distribution's median, whereas the box represents the interquartile range. Dots resemble outliers. Mean NCIQ is displayed by the red line. b Box plot illustration of the APHAB total score and their four domains (EC, $\mathrm{RV}, \mathrm{BN}$, and $\mathrm{AV}$ ) during the measurement times (preoperative and 12 months after operation) of the total patient cohort
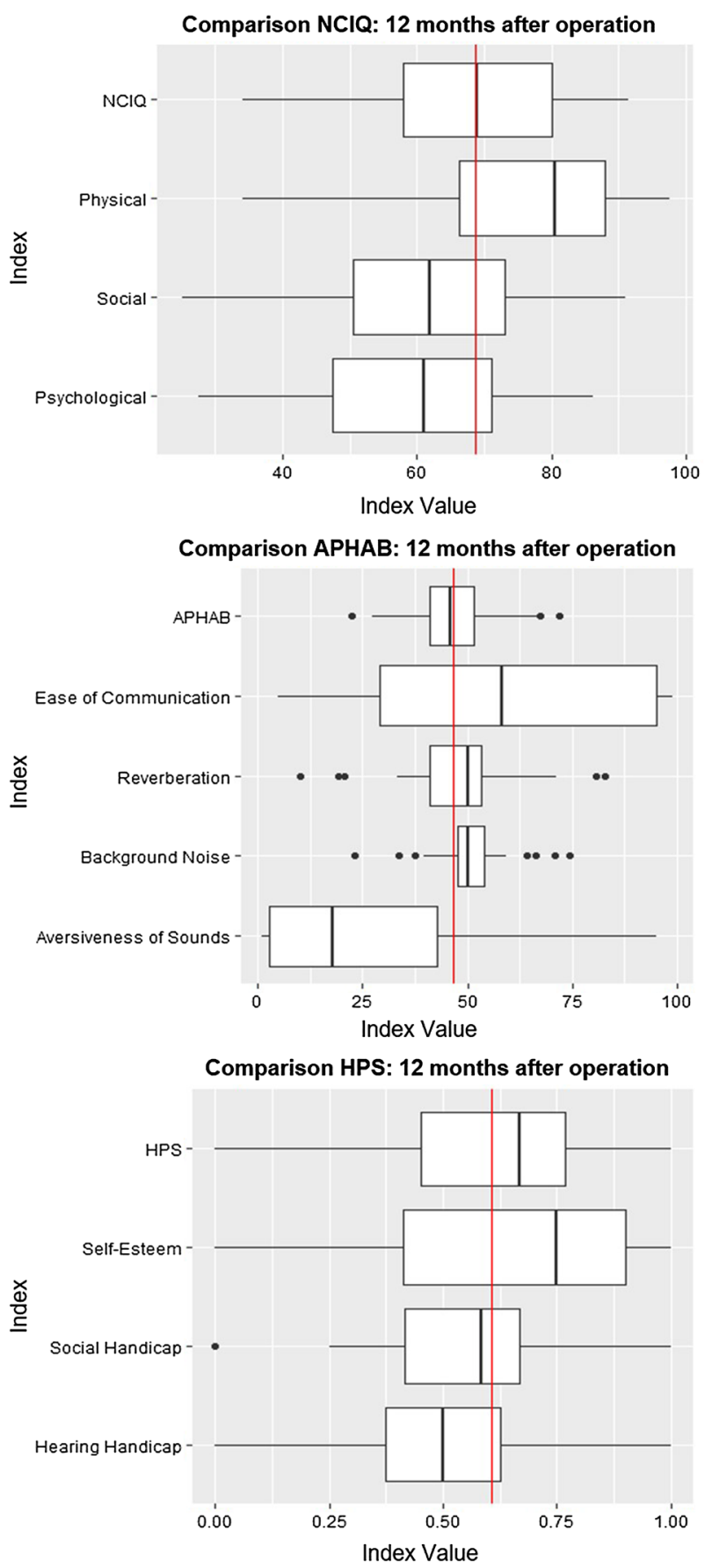

$(n=100)$. The red line represents the overall mean NCIQ score. The bold line shows each distribution's median, whereas the box represents the interquartile range. Dots resemble outliers. Mean APHAB is displayed by the red line. c Box plot illustration of the HPS total score and their three domains (self-esteem, social, and hearing handicap) after implantation (3 months after operation and 12 months after operation) of the total patient cohort $(n=100)$. The red line represents the overall mean HPS score. The bold line shows each distribution's median, whereas the box represents the interquartile range. Dots resemble outliers 
Table 1 Overview of the disease-specific questionnaire results of the total patient cohort $(n=100)$ over time

\begin{tabular}{|c|c|c|c|c|c|c|}
\hline $\begin{array}{l}\text { Disease-specific } \\
\text { questionnaire }\end{array}$ & Before implantation & $\begin{array}{l}3 \text { months after } \\
\text { implantation }\end{array}$ & $\begin{array}{l}6 \text { months after } \\
\text { implantation }\end{array}$ & $\begin{array}{l}12 \text { months } \\
\text { after implanta- } \\
\text { tion }\end{array}$ & $\begin{array}{l}p \text { value before } \\
\text { implantation to } \\
12 \text { months after } \\
\text { implantation }\end{array}$ & $\begin{array}{l}\text { Absolute change } \\
\text { after } 12 \text { months }\end{array}$ \\
\hline \multicolumn{7}{|c|}{ Nijmegen cochlear implant questionnaire (NCIQ) } \\
\hline Overall & $49.35 \pm 17.40$ & $63.52 \pm 14.76$ & $67.03 \pm 13.14$ & $68.64 \pm 13.75$ & $<0.01$ & +19.29 \\
\hline Physical & $56.37 \pm 20.48$ & $70.55 \pm 16.36$ & $74.49 \pm 13.53$ & $76.21 \pm 14.63$ & $<0.01$ & +19.84 \\
\hline $\begin{array}{l}\text { Basic sound per- } \\
\text { ception }\end{array}$ & $48.11 \pm 22.28$ & $67.26 \pm 19.34$ & $72.88 \pm 13.99$ & $74.12 \pm 15.64$ & & +26.01 \\
\hline $\begin{array}{l}\text { Advanced sound } \\
\text { perception }\end{array}$ & $70.33 \pm 22.62$ & $80.39 \pm 17.95$ & $81.89 \pm 17.50$ & $84.58 \pm 16.95$ & & +14.25 \\
\hline Speech production & $50.68 \pm 24.37$ & $64.01 \pm 19.75$ & $68.69 \pm 18.54$ & $69.92 \pm 19.07$ & & +19.24 \\
\hline Psychological & $43.82 \pm 18.38$ & $55.89 \pm 17.56$ & $59.45 \pm 15.87$ & $59.72 \pm 15.71$ & $<0.01$ & +15.90 \\
\hline Self-esteem & $43.82 \pm 18.38$ & $55.89 \pm 17.56$ & $59.45 \pm 15.87$ & $59.72 \pm 15.71$ & & +15.90 \\
\hline Social & $41.84 \pm 15.98$ & $56.38 \pm 15.47$ & $59.50 \pm 15.12$ & $61.45 \pm 15.78$ & $<0.01$ & +19.61 \\
\hline Activity limitations & $42.05 \pm 18.86$ & $57.43 \pm 17.77$ & $60.16 \pm 18.31$ & $62.83 \pm 18.67$ & & +20.78 \\
\hline Social interactions & $41.63 \pm 15.38$ & $55.32 \pm 16.01$ & $58.84 \pm 13.81$ & $60.08 \pm 14.87$ & & +18.45 \\
\hline \multicolumn{7}{|c|}{ Abbreviated profile of hearing aid benefit (APHAB) } \\
\hline Overall & $46.80 \% \pm 13.03$ & $46.16 \% \pm 10.56$ & $47.91 \% \pm 11.63$ & $46.57 \% \pm 10.17$ & $\begin{array}{c}\text { Without HA: } 0.99 \\
\text { with HA: } 0.24\end{array}$ & -0.23 \\
\hline $\begin{array}{l}\text { Ease of communi- } \\
\text { cation (EC) }\end{array}$ & $61.15 \% \pm 33.94$ & $57.91 \% \pm 34.35$ & $58.05 \% \pm 34.42$ & $60.26 \% \pm 33.11$ & $\begin{array}{c}\text { Without HA: } 0.29 \\
\text { with HA: } \mathbf{0 . 0 1}\end{array}$ & -0.89 \\
\hline $\begin{array}{l}\text { Background noise } \\
\text { (BN) }\end{array}$ & $49.34 \% \pm 11.62$ & $50.41 \% \pm 11.22$ & $50.21 \% \pm 10.69$ & $50.66 \% \pm 8.42$ & $\begin{array}{c}\text { Without HA: } 0.79 \\
\text { with HA: } 0.56\end{array}$ & +1.32 \\
\hline $\begin{array}{l}\text { Reverberation } \\
\text { (RV) }\end{array}$ & $49.60 \% \pm 15.16$ & $49.29 \% \pm 13.44$ & $49.84 \% \pm 12.01$ & $48.83 \% \pm 13.27$ & $\begin{array}{c}\text { Without HA: } 0.79 \\
\text { with HA: } 0.72\end{array}$ & -0.77 \\
\hline $\begin{array}{l}\text { Aversiveness of } \\
\text { sounds (AV) }\end{array}$ & $28.70 \% \pm 28.99$ & $26.84 \% \pm 27.41$ & $30.26 \% \pm 28.08$ & $26.46 \% \pm 26.13$ & $\begin{array}{c}\text { Without HA: } \mathbf{0 . 0 2} \\
\text { with HA: } 0.56\end{array}$ & -2.24 \\
\hline \multicolumn{7}{|c|}{ Hearing participation scale (HPS) } \\
\hline Overall & NA & $0.58 \pm 0.24$ & $0.61 \pm 0.24$ & $0.61 \pm 0.24$ & $0.21 *$ & +0.03 \\
\hline Self-esteem & NA & $0.66 \pm 0.26$ & $0.66 \pm 0.27$ & $0.66 \pm 0.27$ & $0.75^{*}$ & 0 \\
\hline Social handicap & NA & $0.57 \pm 0.19$ & $0.54 \pm 0.18$ & $0.54 \pm 0.18$ & $0.19 *$ & -0.03 \\
\hline Hearing handicap & NA & $0.60 \pm 0.21$ & $0.49 \pm 0.21$ & $0.49 \pm 0.21$ & $0.004 *$ & -0.11 \\
\hline \multicolumn{7}{|c|}{ Visual Analogue Scale (VAS) } \\
\hline Overall & NA & $75.57 \pm 20.36$ & $77.26 \pm 18.63$ & $74.84 \pm 21.66$ & $0.64 *$ & -0.73 \\
\hline
\end{tabular}

Values are mean and standard deviation. Significant changes are marked in bold. Unlike NCIQ and APHAB scores, the $p$ values of HPS and VAS scores were calculated from the 3-month to 12-month follow-up and are indicated with an asterisk

$N A$ not available, $H A$ hearing aid

We used PCA and EFA to test the six subcategories of the three NCIQ domains as previously described [21], aiming to verify the established assumptions of the classification of subindices. The graphical and non-graphical approaches of PCA suggest a model composed of three components rather than six components. However, we performed an EFA for a six- and three-component model. We found that a three-component model only describes $39 \%$ of the index's variance. Since the addition of three more components only explained a further $4 \%$ of the variance, the three-component model should be preferred. This makes PCA of utmost importance as 'hypothesis generating' tool creating a simple and clear principal component construct. The basic sound perception and speech production subcategories of the physical domain were loaded on factor 1 , whereas the advanced sound perception subcategory of the physical domain fitted into factor 3. Factor 2 included scores from the social and psychological subdomains, which we collectively termed the sociopsychological domain.

\section{Abbreviated profile of hearing aid benefit (APHAB)}

The APHAB score decreased over time, except for the BN subscale (Fig. 1b, Table 1). The preoperative and postoperative APHAB scores were not significantly different in patients who did not wear a hearing aid, whereas scores 
in patients who wore a hearing aid increased significantly after implantation (3 months: $p=0.056$; 6 months: $p<0.01$ ). Scores were significantly lower in unilaterally deaf patients than in bilaterally deaf patients at the 6-month follow-up (45.9 vs. $51.8 \% ; p=0.05$ ), indicating that bilaterally deaf patients experience less postoperative benefit than unilaterally deaf patients do. Unilaterally deaf patients who did not wear a hearing aid had significantly lower scores in the EC subdomain before and after implantation $(p<0.01)$, indicating that a CI improved EC for those patients. Scores in the $\mathrm{RV}$ and $\mathrm{BN}$ subdomains were not significantly different between the groups at any time point $(p>0.05)$. Patients who did not wear a hearing aid had significantly higher scores in the AV subdomain before implantation (22.2 vs. $36.4 \%$; $p=0.02$ ), 3 months after implantation (20.6 vs. $35.0 \% ; p=0.02)$, and 12 months after implantation (19.4 vs. $34.1 \%$; $p=0.03$ ), indicating lower satisfaction for these patients. Bilaterally deaf patients had significantly lower scores in the AV subdomain at all time points $(p<0.01)$. The degree of impairment also affected scores in the EC subdomain at all time points in patients who did not wear a hearing aid (before: $\widehat{\beta}=23.49, p<0.01$ ). Age influenced the APHAB score at 12 months after implantation in patients who wore a hearing aid $(\hat{\beta}=0.49, p=0.05)$. Scores in the RV subdomain were influenced by marital status only in patients without a hearing aid before: $(\hat{\beta}=5.79, p=0.04)$ and by graduation (before: $\widehat{\beta}=6.66, p=0.01$ ) in patients with a hearing aid. Scores in the $\mathrm{BN}$ subdomain were influenced by gender, graduation, and professional activity before implantation in patients without a hearing aid, and by age and gender 3 months after implantation in patients with a hearing aid. Gender and degree of hearing impairment affected AV scores before and after implantation in patients without a hearing aid. In patients with a hearing aid, AV scores were affected by the degree of hearing impairment before and 3- and 6-month cochlear implantation. Gender affected AV scores at 12 months after implantation $(\hat{\beta}=-19.68, p=0.01)$.

We verified the system described by Cox and Alexander [32] using PCA and EFA, which revealed a two-component model of APHAB, that significantly $(p<0.001)$ explained $59 \%$ of the total variance. Items $1-2,4-7,9-10,12,14-16$, $18-19,21,23$, and 24 were loaded on component 1 , corresponding to $\mathrm{EC}, \mathrm{BN}$, and $\mathrm{RV}$, while the rest of the items fitted into component 2 (similar to AV).

\section{Hearing participation scale (HPS)}

HPS scores improved slightly over time and stabilized from 6 to 12 months after implantation (Fig. 1c, Table 1). The hearing handicap subscore significantly deteriorated from 3 to 12 months after implantation, indicating greater hearing impairment over time. Wearing a hearing aid or degree of hearing impairment did not affect the scores over time, and there were no differences in the three subscores between groups. Professional activity affected the HPS score at the 3 -month follow-up $(\hat{\beta}=-0.08, p=0.01)$.

PCA and EFA analyses revealed that the HPS score can be better explained by two components, which explain $45 \%$ of the total variance. The addition of a third component only explained a further $6 \%$ of the variance. Questions 1-4 and $8-11$ were loaded to factor 1 , which comprised questions on self-esteem and hearing handicap. These questions were recently summarized as an overall effect of the hearing handicap on QoL. Questions 5-7 were assigned to factor 2, largely in agreement with the pre-existing social handicap.

\section{Comparisons between the questionnaires}

Pearson correlation coefficients showed a significant negative correlation between the APHAB and the NCIQ scores before implantation $(\hat{\rho}=-0.22, p=0.03)$ and at 3 months $(\hat{\rho}=-0.25, p=0.03)$ and 12 months $(\hat{\rho}=-0.33, p=0.02)$ after implantation. The APHAB did not significantly correlate with the VAS and the HPS scores, but there was a significant correlation between the NCIQ and the HPS scores $(\hat{\rho}=0.29, p<0.01)$. NCIQ scores significantly correlated with VAS scores at the 6-month and 12-month follow-up $(\hat{\rho}=0.35 ; \hat{\rho}=0.31, p<0.01)$. There was also a significant correlation between HPS scores and VAS scores (Fig. 2).

\section{Discussion}

Measuring the HRQoL is becoming more important in clinical and research settings [19]. To thoroughly assess QoL, both generic and disease-specific questionnaires should be used [12, 26, 33]. The use of generic instruments, such as the HUI3, is recommended [34] to provide the health-economic evaluations underpinning commissioning decisions in publicly funded healthcare systems [33]. As generic QoL measures capture a wide range of aspects in the health status of a person [35], they focus on conditions that may not be influenced by cochlear implantation and, therefore, they tend to be less sensitive [18] to evaluate subjective outcomes and QoL changes induced by cochlear implantation. Addressing this question was the main goal of our study, and that is why, we exclusively used disease-specific instruments. QoL measurements in patients fitted with CIs can be compared systematically between patient groups. In this study, we compared unilaterally and bilaterally hearing-impaired patients and patients with and without a hearing aid using the NCIQ, APHAB, and HPS questionnaires to assess the patients' perception of their QoL before and after cochlear implantation. 

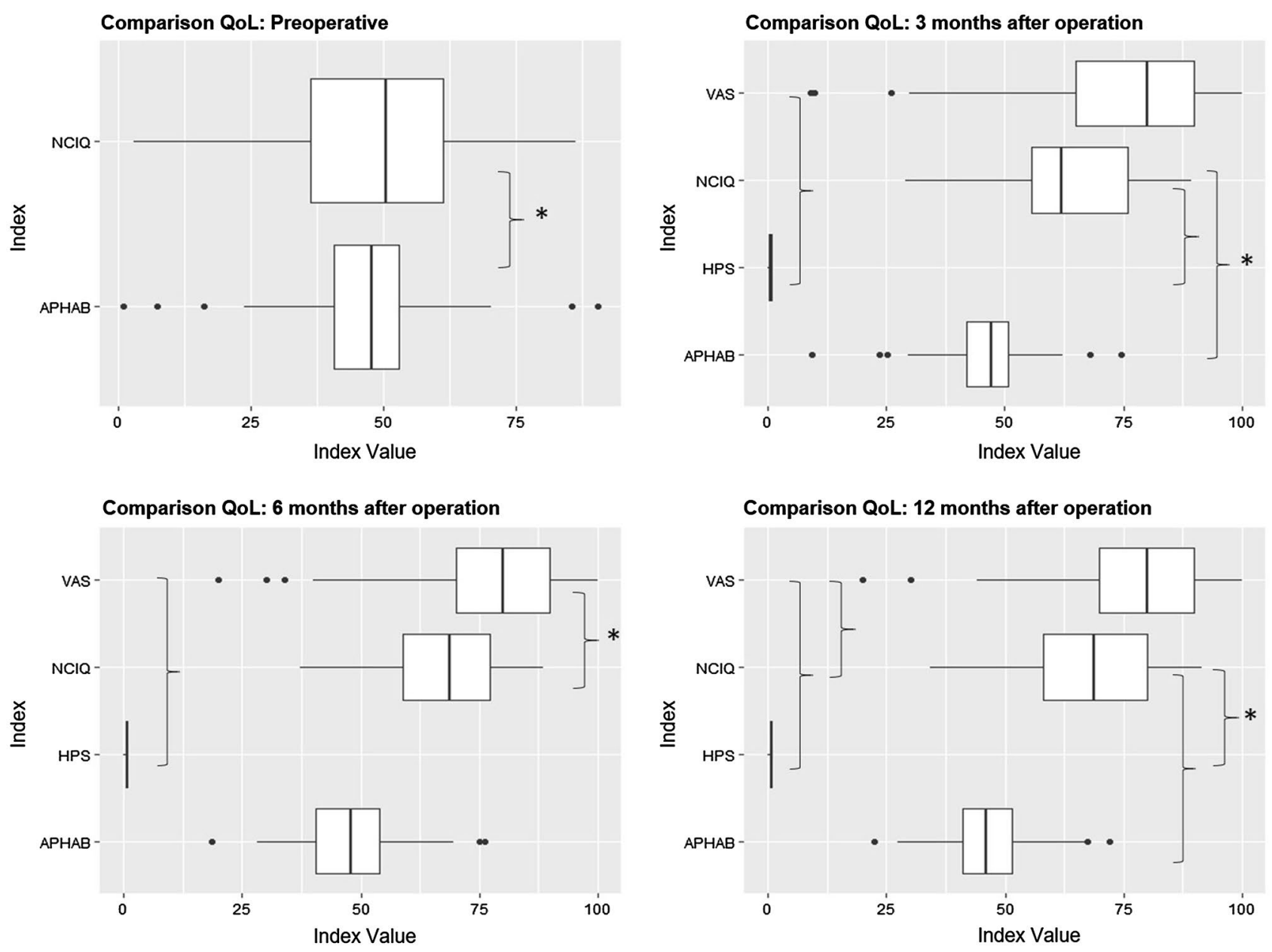

Fig. 2 Box plot illustration of the correlation between the different, here selected questionnaires at different time points (preoperative, 3 months after operation, 6 months after operation, and 12 months after operation) of the total patient cohort $(n=100)$. Significant corre-

As described in diverse studies, the NCIQ, developed by Hinderink et al. to encompass not only hearing and speech production but also the psychological and social domains [21], measured important improvements in the NCIQ total score as well as in all six domains between the CI-pre and CI-post assessments $[1,8,9,13,21,36]$. In line with the previous studies, we observed the largest improvement in the basic sound perception subdomain of the physical domain $[13,21]$ followed by the activity limitations subdomain of the social domain. This is understandable, because progressive hearing loss significantly affects a person's social life. For example, in social situations where lots of people are speaking, a person with hearing impairment will find it challenging to follow simple conversations [37], creating a feeling of profound social isolation and reduced QoL [38, 39]. In agreement with the findings of Hinderink et al. [21], we observed that a CI not only improves hearing and speech production, but also improves self-esteem, daily activities,

lations are marked with brackets and an asterisk $(* p<0.05)$. A higher NCIQ score indicates better results, whereas a higher APHAB score indicates a worse result. High HPS scores indicate little impairment, whereas lower scores indicate greater impairment or social handicap

and social functioning. Contrary to the results of Hinderink et al. [21] and Krabbe et al. [13], we observed the lowest improvement in the advanced sound perception subdomain (physical subdomain). This may be because a single CI can improve speech recognition and fulfill a person's basic auditory needs, but bilaterally deaf people still find it difficult to listen in environments with high background noise and multiple speakers. The inability to perceive the directionality of sound makes this even more difficult [40]. However, the NCIQ subscores revealed physical benefits in bilaterally deaf patients who wear a hearing aid after unilateral cochlear implantation, emphasizing that a CI may improve QoL [37].

Based on the recommendation of Kitterick et al. [33] for assessing hearing-related quality of life, we also used the APHAB to quantify hearing difficulties in everyday listening situations [32]. In accordance with the findings of Zwartenkot et al. [25], we found that APHAB scores improved over time, except for $\mathrm{BN}$, indicating a positive effect of cochlear 
implantation on HRQoL. As described by Zwartenkot et al. [25], the deterioration of $\mathrm{BN}$ could be due to progressive hearing loss (similar to slowly progressing presbyacusis). We showed that a unilateral CI significantly improved EC for unilaterally deaf patients who do not wear a hearing aid. However, we did not see any differences in the ability to hear in reverberate situations or in situations with background noise between the groups. At the moment, we cannot explain this finding. Bilaterally deaf patients who wore a hearing aid had significantly more aversiveness to sounds over time, which indicates negative reactions to environmental sounds [25]. Consequently, having cochlear implants in both ears may help people to hear better in noisy places and find where sounds came from [37]. Studies have shown that QoL improves more after bilateral cochlear implantation [1] than after unilateral cochlear implantation, and that EC, BN, and $\mathrm{RV}$ are improved [41, 42]. This explains why patients fitted with unilateral CIs generally express a desire for bilateral implants [37]. However, the VAS scores reported here show that bilaterally deaf patients were significantly more satisfied with their CIs than unilaterally deaf patients were. Generally, there is an ongoing global discussion on whether or not bilateral cochlear implantation should be standard care for bilateral deafness. In this context, the study group of Ramakers et al. reported on the positive effect of bilateral cochlear implantation on preoperative tinnitus complaints, which should be taken into account when counseling a patient [43]. Taken together, these findings show that cochlear implantation is a successful treatment for improving QoL in deaf patients, and that both the NCIQ and the APHAB seems to be good hearing instruments in adults with a unilaterally and bilaterally severe to profound sensorineural hearing loss. Hearing impairment can also be evaluated using the HPS questionnaire. In agreement with the findings of Hogan and Hawthorne [10, 44], the total HPS score improved over time and stabilized between 6 and 12 months after implantation. However, contrary to their findings, we could not confirm an improvement in the subscores. Instead, we observed that the hearing handicap subscore significantly deteriorated between 3 and 12 months after implantation, indicating greater hearing impairment over time. This could be a natural consequence of aging.

The heterogeneity of our results may be explained by the different questionnaires used, each of which uses different factors to assess QoL. Standardized CI-specific HRQoL instruments would help here. In the present study, we have shown that the NCIQ is a good first-line questionnaire for assessing QoL in deaf patients after cochlear implantation. NCIQ scores correlated well with those of other QoL instruments, and the NCIQ has a plausible three-domain factor classification.

With the aim to either verify the established (sub)domain classification of the questionnaires or suggest possible changes that may further help to reduce the high-dimensionality of the questionnaires into few (mostly) uncorrelated components, we used PCA and EFA. These proposed novel assignments of items to particular components. The NCIQ score can be explained by three components based on the original division by Hinderink et al. [21] but with different assignments. These three components are physical, physical advanced, and socio-psychological. For the APHAB developed by Cox and Alexander [32], the PCA revealed a two-factor solution, with $\mathrm{EC}, \mathrm{RV}$, and $\mathrm{BN}$ comprising factor 1 and AV comprising factor 2. The original three HPS components described by Hawthorne and Hogan [26] can be better explained by two components, which we call overall effect of the hearing handicap on QoL and social handicap.

We observed only a weak socio-demographic influence on the questionnaire scores. Similar to the findings of Bess et al. [45], the degree of hearing loss influenced the level of physical disability measured by the NCIQ. We also showed that the degree of hearing impairment affected the EC and AV subdomains of the APHAB as well as the VAS scores. We also saw no clear effect of age on QoL scores, so included patients from 18.7 to 87.4 years of age rather than focusing on elderly patients like in the studies of Dalton et al. [46] and Nordvik et al. [23]. Our finding that age at implantation is not directly linked to HRQoL is supported by the other studies $[8,47,48]$.

There are some limitations to the present study. Assessing QoL is limited by the survey designs, which do not consider cognitive or communicative abilities and whether the patients can assess their own functional limitations. A further criticism is that patient satisfaction is extremely subjective [49], and results can be biased by context effects, such as the current mood. Our attrition rate of $41 \%$ after 12 months introduces the possibility of selection bias [19], which may have affected the results. The impact is more obvious for the estimators' variances, since these will be increased due to the reduction in sample sizes. The impact may, therefore, produce false negative results, especially when regarding the significance of characteristics influencing an index's outcome. However, due to the magnitude of significance in our findings, it may be assumed that this particular effect has not occurred. It is, therefore, more likely that we neglected influences that would have been significant, given a larger sample size. To mitigate such problems, we opted for a variance estimation based on Monte Carlo simulations for our comparisons. Nevertheless, since the Monte Carlo variance is also an estimate and cannot reduce the impact of a small sample size in its entirety, the generalizability of these results is limited. Another important limitation, however, is that the attrition may have been systematic and may be the result of socio-demographic or socio-psychological characteristic as well as extrinsic shocks. This may then in turn also have influenced the biasedness of our estimates. Given the limited 
data points available, we can only assume that our findings would hold true when reproduced with a larger sample size.

Furthermore, the prospective study design may have introduced recalibration, reprioritization, and reconceptualization response shifts in the post-test phase [50]. However, response shifts are probably minimal in CI patients, because they re-experience deafness whenever they remove their speech processor.

Our study also has some strengths. Most previous studies have assessed QoL retrospectively, after cochlear implantation and with low patients' numbers and measurement time points $[8,9,13,21]$. In contrast, our study has a prospective study design, uses three disease-specific questionnaires, and measures QoL before implantation and at three time points after implantation. Further research is needed to explore long-term changes in QoL after cochlear implantation.

\section{Conclusions}

Assessing HRQoL after cochlear implantation using standardized and validated disease-specific questionnaires is an important part of audiological diagnostics. Results from standardized QoL questionnaires can be compared between different studies to monitor the effects of technical improvements to cochlear implantation. We suggest that the NCIQ be used as a first-line questionnaire to assess psychological, social, and physical domains as these results correlated significantly with those of different questionnaires.

\begin{abstract}
Author contributions All authors made substantial contributions to the study. MiP: participated in data acquisition and analysis, interpreted the data, and drafted the manuscript; TM: designed and coordinated the study, participated in data acquisition and analysis, and interpreted the data; MS: is an accredited expert of survey analysis, who is working for GESIS-Leibniz Institute for Social Sciences with headquarter in Mannheim, and participated in data interpretation, statistical analysis, and revision of the manuscript; PSvdW: participated in data acquisition and analysis and interpreted the data; MaP: participated in revision of the manuscript; PKP: participated in revision of the manuscript; IB: designed and coordinated the study, participated in data acquisition and analysis, and critically revised the manuscript for important intellectual content; KZ: participated in data interpretation, data acquisition, and analysis, and critically revised the manuscript.
\end{abstract}

Funding Open Access funding enabled and organized by Projekt DEAL. No external/additional funding was received for this study.

Data availability The datasets generated during and/or analyzed during the current study are available from the corresponding author on reasonable request.

\section{Compliance with ethical standards}

Conflict of interest All authors declare that they have no conflict of interest.

Ethics approval The ethics committee of the Medical Faculty at the University of Heidelberg granted permission to conduct the study (project no S-481/2009). The study was performed according to the Declaration of Helsinki on biomedical research involving human subjects. All patients were informed about the study aims and protocol, and participants were enrolled after giving informed written consent.

Consent to participate Informed consent was obtained from all individual participants included in the study.

Open Access This article is licensed under a Creative Commons Attribution 4.0 International License, which permits use, sharing, adaptation, distribution and reproduction in any medium or format, as long as you give appropriate credit to the original author(s) and the source, provide a link to the Creative Commons licence, and indicate if changes were made. The images or other third party material in this article are included in the article's Creative Commons licence, unless indicated otherwise in a credit line to the material. If material is not included in the article's Creative Commons licence and your intended use is not permitted by statutory regulation or exceeds the permitted use, you will need to obtain permission directly from the copyright holder. To view a copy of this licence, visit http://creativecommons.org/licenses/by/4.0/.

\section{References}

1. Cohen SM, Labadie RF, Dietrich MS, Haynes DS (2004) Quality of life in hearing-impaired adults: the role of cochlear implants and hearing aids. Otolaryngol Head Neck Surg 131(4):413-422. https://doi.org/10.1016/j.otohns.2004.03.026

2. Homans NC, Metselaar RM, Dingemanse JG, van der Schroeff MP, Brocaar MP, Wieringa MH, Baatenburg de Jong RJ, Hofman A, Goedegebure A (2017) Prevalence of age-related hearing loss, including sex differences, in older adults in a large cohort study. Laryngoscope 127(3):725-730. https://doi.org/10.1002/ lary. 26150

3. Oosterloo BC, Homans NC, Baatenburg de Jong RJ, Ikram MA, Nagtegaal AP, Goedegebure A (2020) Assessing hearing loss in older adults with a single question and person characteristics; comparison with pure tone audiometry in the Rotterdam study. PLoS ONE 15(1):e0228349. https://doi.org/10.1371/journ al.pone. 0228349

4. National Council on the Aging (2000) The consequences of untreated hearing loss in older persons. ORL Head Neck Nurs 18(1):12-16

5. Tretbar K, Basilowski M, Wiedmann K, Bartels C, Hessmann P, Kownatka M, Signerski-Krieger J, Scherbaum N, Meuret S, Fuchs M, Wiltfang J, Kis B, Abdel-Hamid M (2019) Quality of life and depression in hearing-impairment: a German survey. HNO 67(1):36-44. https://doi.org/10.1007/s00106-018-0576-4

6. Vist GE, Forsetlund L, Odgaard-Jensen J (2006). In: Cochlear implants in adults. NIPH systematic reviews: executive summaries. The Norwegian Institute of Public Health, Oslo, Norway

7. Martini A, Bovo R, Trevisi P, Forli F, Berrettini S (2013) [Cochlear implant in children: rational, indications and cost/efficacy]. Minerva Pediatr 65(3):325-339

8. Hirschfelder A, Grabel S, Olze H (2008) The impact of cochlear implantation on quality of life: the role of audiologic performance 
and variables. Otolaryngol Head Neck Surg 138(3):357-362. https ://doi.org/10.1016/j.otohns.2007.10.019

9. Damen GW, Beynon AJ, Krabbe PF, Mulder JJ, Mylanus EA (2007) Cochlear implantation and quality of life in postlingually deaf adults: long-term follow-up. Otolaryngol Head Neck Surg 136(4):597-604. https://doi.org/10.1016/j.otohns.2006.11.044

10. Hawthorne G, Hogan A, Giles E, Stewart M, Kethel L, White K, Plaith B, Pedley K, Rushbrooke E, Taylor A (2004) Evaluating the health-related quality of life effects of cochlear implants: a prospective study of an adult cochlear implant program. Int J Audiol 43(4):183-192. https://doi.org/10.1080/14992020400050026

11. Maillet CJ, Tyler RS, Jordan HN (1995) Change in the quality of life of adult cochlear implant patients. Ann Otol Rhinol Laryngol Suppl 165:31-48

12. Mo B, Lindbaek M, Harris S (2005) Cochlear implants and quality of life: a prospective study. Ear Hear 26(2):186-194. https://doi. org/10.1097/00003446-200504000-00006

13. Krabbe PF, Hinderink JB, van den Broek P (2000) The effect of cochlear implant use in postlingually deaf adults. Int J Technol Assess Health Care 16(3):864-873. https://doi.org/10.1017/s0266 462300102132

14. Lenarz M, Sonmez H, Joseph G, Buchner A, Lenarz T (2012) Cochlear implant performance in geriatric patients. Laryngoscope 122(6):1361-1365. https://doi.org/10.1002/lary.23232

15. Hiraumi H, Tsuji J, Kanemaru S, Fujino K, Ito J (2007) Cochlear implants in post-lingually deafened patients. Acta Otolaryngol 557:17-21. https://doi.org/10.1080/03655230601065225

16. Hoppe U, Hocke T, Hast A, Iro H (2019) Maximum preimplantation monosyllabic score as predictor of cochlear implant outcome. HNO 67(2):62-68. https://doi.org/10.1007/s00106-019-0648-0

17. Wesarg T, Arndt S, Alballaa AS, Rauch AK, Laszig R, Aschendorff A, Speck I (2019) [Dichotic speech recognition with cochlear implants]. HNO 67(10):769-777. https://doi.org/10.1007/ s00106-019-00728-9

18. Loeffler C, Aschendorff A, Burger T, Kroeger S, Laszig R, Arndt S (2010) Quality of life measurements after cochlear implantation. Open Otorhinolaryngol J 4:47-54

19. Mistry D, Ryan J, Maessen H, Bance M (2014) Differences in perception of hearing handicap between cochlear implant users and their spouses. Laryngoscope 124(5):1199-1203. https://doi. org/10.1002/lary.24404

20. Brazier J, Deverill M, Green C (1999) A review of the use of health status measures in economic evaluation. J Health Serv Res Policy 4(3):174-184. https://doi.org/10.1177/135581969900400 310

21. Hinderink JB, Krabbe PF, Van Den Broek P (2000) Development and application of a health-related quality-of-life instrument for adults with cochlear implants: the Nijmegen cochlear implant questionnaire. Otolaryngol Head Neck Surg 123(6):756-765. https://doi.org/10.1067/mhn.2000.108203

22. Wexler M, Miller LW, Berliner KI, Crary WG (1982) Psychological effects of cochlear implant: patient and "index relative" perceptions. Ann Otol Rhinol Laryngol Suppl 91(2 Pt 3):59-61

23. Nordvik O, Laugen Heggdal PO, Brannstrom J, Vassbotn F, Aarstad AK, Aarstad HJ (2018) Generic quality of life in persons with hearing loss: a systematic literature review. BMC Ear Nose Throat Disord 18:1. https://doi.org/10.1186/s12901-018-0051-6

24. Sanhueza I, Manrique-Huarte R, Calavia D, Huarte A, Manrique M (2019) Hearing impairment and quality of life in adults with asymmetric hearing loss: benefits of bimodal stimulation. J Int Adv Otol 15(1):62-69. https://doi.org/10.5152/iao.2019.6224

25. Zwartenkot JW, Hashemi J, Cremers CW, Mulder JJ, Snik AF (2013) Active middle ear implantation for patients with sensorineural hearing loss and external otitis: long-term outcome in patient satisfaction. Otol Neurotol 34(5):855-861. https://doi. org/10.1097/MAO.0b013e31828f47c2

26. Hawthorne G, Hogan A (2002) Measuring disability-specific patient benefit in cochlear implant programs: developing a short form of the glasgow health status inventory, the hearing participation scale. Int J Audiol 41(8):535-544. https://doi. org/10.3109/14992020209056074

27. Price DD, McGrath PA, Rafii A, Buckingham B (1983) The validation of visual analogue scales as ratio scale measures for chronic and experimental pain. Pain 17(1):45-56. https://doi. org/10.1016/0304-3959(83)90126-4

28. Kaiser HF (1960) The application of electronic computers to factor analysis. Educ Psychol Meas 20(1):141-151

29. Cattell RB (1966) The Scree test for the number of factors. Multivariate Behav Res 1(2):245-276. https://doi.org/10.1207/s1532 7906mbr0102_10

30. James G, Witten D, Hastie T, Tibshirani R (2013) An introduction to statistical learning: with applications in R. Springer, New York

31. Lugtig P (2014) Panel attrition: separating stayers, fast attriters, gradual attriters, and lurkers. Sociol Methods Res 43(4):699-723

32. Cox RM, Alexander GC (1995) The abbreviated profile of hearing aid benefit. Ear Hear 16(2):176-186. https://doi. org/10.1097/00003446-199504000-00005

33. Kitterick PT, Smith SN, Lucas L (2016) Hearing instruments for unilateral severe-to-profound sensorineural hearing loss in adults: a systematic review and meta-analysis. Ear Hear 37(5):495-507. https://doi.org/10.1097/AUD.0000000000000313

34. Ramakers GG, Smulders YE, van Zon A, Kraaijenga VJ, Stegeman I, Van Zanten GA, Grolman W (2016) Agreement between health utility instruments in cochlear implantation. Clin Otolaryngol 41(6):737-743. https://doi.org/10.1111/coa.12626

35. Fitzpatrick R, Davey C, Buxton MJ, Jones DR (1998) Evaluating patient-based outcome measures for use in clinical trials. Health Technol Assess 2(14):1-74. https://doi.org/10.3310/hta2140

36. Haussler SM, Knopke S, Dudka S, Grabel S, Ketterer MC, Battmer RD, Ernst A, Olze H (2020) Improvement in tinnitus distress, health-related quality of life and psychological comorbidities by cochlear implantation in single-sided deaf patients. HNO 68(1):110. https://doi.org/10.1007/s00106-019-0705-8

37. Ontario HQ (2018) Bilateral cochlear implantation: a health technology assessment. Ont Health Technol Assess Ser 18(6):1-139

38. Ciorba A, Bianchini C, Pelucchi S, Pastore A (2012) The impact of hearing loss on the quality of life of elderly adults. Clin Interv Aging 7:159-163. https://doi.org/10.2147/CIA.S26059

39. Mick P, Kawachi I, Lin FR (2014) The association between hearing loss and social isolation in older adults. Otolaryngol Head Neck Surg 150(3):378-384. https://doi.org/10.1177/0194599813 518021

40. Schramm D (2010) Canadian position statement on bilateral cochlear implantation. J Otolaryngol Head Neck Surg 39(5):479-485

41. Litovsky R, Parkinson A, Arcaroli J, Sammeth C (2006) Simultaneous bilateral cochlear implantation in adults: a multicenter clinical study. Ear Hear 27(6):714-731. https://doi.org/10.1097/01. aud.0000246816.50820.42

42. van Zon A, Smulders YE, Stegeman I, Ramakers GG, Kraaijenga VJ, Koenraads SP, Zanten GA, Rinia AB, Stokroos RJ, Free RH, Frijns JH, Huinck WJ, Mylanus EA, Tange RA, Smit AL, Thomeer HG, Topsakal V, Grolman W (2017) Stable benefits of bilateral over unilateral cochlear implantation after two years: a randomized controlled trial. Laryngoscope 127(5):1161-1168. https://doi.org/10.1002/lary.26239

43. Ramakers GGJ, Kraaijenga VJC, Smulders YE, van Zon A, Stegeman I, Stokroos RJ, Free RH, Frijns JHM, Huinck WJ, Van Zanten GA, Grolman W (2017) Tinnitus after simultaneous and 
sequential bilateral cochlear implantation. Front Surg 4:65. https ://doi.org/10.3389/fsurg.2017.00065

44. Hogan A, Hawthorne G, Kethel L, Giles E, White K, Stewart M, Plath B, Code C (2001) Health-related quality-of-life outcomes from adult cochlear implantation: a cross-sectional survey. Cochlear Implants Int 2(2):115-128. https://doi.org/10.1179/ cim.2001.2.2.115

45. Bess FH, Lichtenstein MJ, Logan SA, Burger MC, Nelson E (1989) Hearing impairment as a determinant of function in the elderly. J Am Geriatr Soc 37(2):123-128. https://doi. org/10.1111/j.1532-5415.1989.tb05870.x

46. Dalton DS, Cruickshanks KJ, Klein BE, Klein R, Wiley TL, Nondahl DM (2003) The impact of hearing loss on quality of life in older adults. Gerontologist 43(5):661-668. https://doi. org/10.1093/geront/43.5.661

47. Djalilian HR, King TA, Smith SL, Levine SC (2002) Cochlear implantation in the elderly: results and quality-of-life assessment. Ann Otol Rhinol Laryngol 111(10):890-895. https://doi. org/10.1177/000348940211101005
48. Vermeire K, Brokx JP, Wuyts FL, Cochet E, Hofkens A, Van de Heyning PH (2005) Quality-of-life benefit from cochlear implantation in the elderly. Otol Neurotol 26(2):188-195. https://doi. org/10.1097/00129492-200503000-00010

49. Ondik MP, Lipinski L, Dezfoli S, Fedok FG (2009) The treatment of nasal fractures: a changing paradigm. Arch Facial Plast Surg 11(5):296-302. https://doi.org/10.1001/archfacial.2009.65

50. Blome C, Augustin M (2015) Measuring change in quality of life: bias in prospective and retrospective evaluation. Value Health 18(1):110-115. https://doi.org/10.1016/j.jval.2014.10.007

Publisher's Note Springer Nature remains neutral with regard to jurisdictional claims in published maps and institutional affiliations. 